\title{
GM3 synthase deficiency
}

INSERM

\section{Source}

INSERM. (1999). Orphanet: an online rare disease and orphan drug data base. GM3 synthase deficiency. ORPHA:370933

GM3 synthase deficiency is a rare congenital disorder of glycosylation due to impaired synthesis of complex gang lioside species initially characterized by irritability, poor feeding, failure to thrive and early-onset refractory epilepsy, followed by postnatal growth impairment, severe developmental delay or developmental regression, profound intellectual disability, deafness and abnormalities of skin pigmentation (mostly freckle-like hyperpig mented and depigmented macules). Visual impairment due to cortical atrophy (visible on magnetic resonance imaging), choreoathetosis and hypotonic tetraparesis usually appear gradually. Dysmorphic facial features may be associated. 